\title{
Structural evolution and stability of $\mathrm{Sc}_{2}\left(\mathrm{WO}_{4}\right)_{3}$ after discharge in a sodium-based electrochemical cell
}

\author{
Henrik L. Andersen, ${ }^{\mathrm{a}, \mathrm{b}}$ Othman K. Al Bahri, ${ }^{\mathrm{b}}$ Sergey Tsarev, ${ }^{\mathrm{c}}$ Bernt Johannessen, ${ }^{\mathrm{d}}$ Bernd Schulz, ${ }^{\mathrm{b}}$ \\ Junnan Liu, ${ }^{b}$ Helen E. A. Brand, ${ }^{d}$ Mogens Christensen ${ }^{a}$ and Neeraj Sharma ${ }^{b *}$ \\ $\mathrm{Sc}_{2}\left(\mathrm{WO}_{4}\right)_{3}$, prepared by solid state synthesis and constructed as electrodes, is discharged to different states in half-cell \\ batteries, versus a $\mathrm{Na}$ negative electrode. The structural evolution of the Na-containing electrodes is studied with \\ synchrotron powder X-ray diffraction (PXRD) revealing an increase in microstrain and a gradual amorphization taking place \\ with increasing $\mathrm{Na}$ content in the electrode. This indicates that a conversion reaction takes place in the electrochemical \\ cell. X-ray absorption spectroscopy (XAS) at the tungsten L3 absorption edge shows a reduction in tungsten oxidation \\ state. Variable temperature (VT) PXRD shows that the $\mathrm{Sc}_{2}\left(\mathrm{WO}_{4}\right)_{3}$ electrode remains relatively stable at higher \\ temperatures, while the Na-containing samples undergo a number of phase transitions and/or turn amorphous above \\ $\sim 400{ }^{\circ} \mathrm{C}$. Although, $\mathrm{Sc}_{2}\left(\mathrm{WO}_{4}\right)_{3}$ is a negative thermal expansion (NTE) material only a subtle change of the thermal expansion \\ is found below $400{ }^{\circ} \mathrm{C}$ for the Na-containing electrodes. This work shows the complexity in employing an electrochemical \\ cell to produce $\mathrm{Na}$-containing $\mathrm{Sc}_{2}\left(\mathrm{WO}_{4}\right)_{3}$ and the subsequent phase transitions.
}

\section{Introduction}

Lithium-ion batteries are among the highest energy density batteries on the market and are thus employed in a range of portable electronic devices, electric vehicles and larger-scale storage solutions. ${ }^{1,2}$ Recognizing the limitations, such as the global supply of lithium, and the increasing demand of these batteries, an effort is underway to build feasible sodium and potassium-ion batteries working on the same principles of the commercially available lithium-ion equivalents. ${ }^{3,} 4$ The larger size of the sodium and potassium cations is one of the many challenges and one that may require the use of the unconventional electrode materials to support the reversible insertion/extraction of these ions. Structurally, requirements for such electrode materials include large structural voids and reducible/oxidisable ions. Interestingly, these two factors are present in $\mathrm{Sc}_{2}\left(\mathrm{WO}_{4}\right)_{3}$ and related negative thermal expansion (NTE) materials.

$\mathrm{Sc}_{2}\left(\mathrm{WO}_{4}\right)_{3}$ is known to exhibit NTE over the temperature range 10-1073 K. ${ }^{5}$ The material adopts the orthorhombic crystal structure shown in Figure 1(A). The relatively open framework structure consists of a network of corner sharing $\mathrm{ScO}_{6}$ octahedra and $\mathrm{WO}_{4}$ tetrahedra. ${ }^{6}$ The structure has one Sc site (Sc1) and two distinct $\mathrm{W}$ sites (W1 and W2). Each $\mathrm{ScO}_{6}$ octahedra shares corners with six $\mathrm{WO}_{4}$ tetrahedra and each
$\mathrm{WO}_{4}$ shares corners with four $\mathrm{ScO}_{6}$ octahedra. The NTE mechanism originates from the coupled three-dimensional twisting of the relatively rigid framework polyhedra. ${ }^{5}$ The twisting is caused by the anharmonic thermal vibrations of the bridging oxygen atoms in the structure, Figure $1(\mathrm{~B})$. The combined twisting of polyhedra leads to an anisotropic thermal expansion behavior with contraction along the crystallographic $a$ - and $c$-axes and expansion along the $b$-axis, resulting in an overall decrease in the unit cell volume as function of temperature. ${ }^{5}$

In the present study, the focus is on the structural consequences of using $\mathrm{Sc}_{2}\left(\mathrm{WO}_{4}\right)_{3}$ electrodes as a negative electrode in sodium half-cells in particular during discharge, and the thermal evolution of Na-containing electrodes. This combines the concepts of using this structure type as a potential electrode in next generation sodium-ion batteries and the influence $\mathrm{Na}$-containing electrodes have on the thermal expansion properties of $\mathrm{Sc}_{2}\left(\mathrm{WO}_{4}\right)_{3}$. 


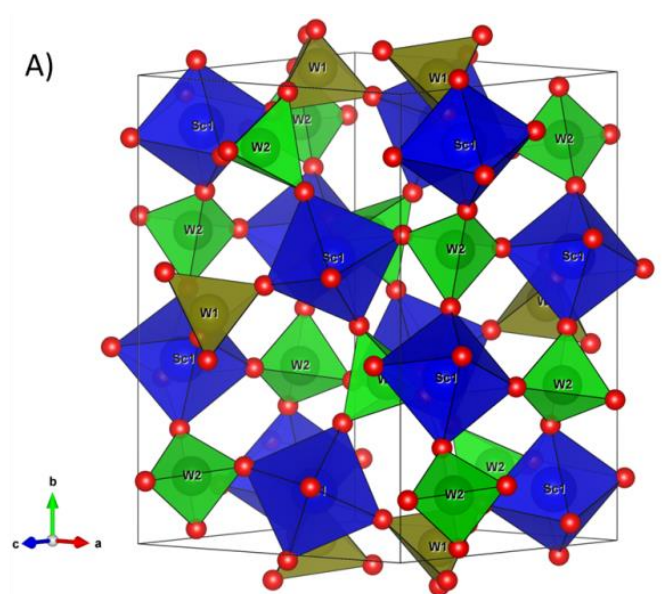

B)

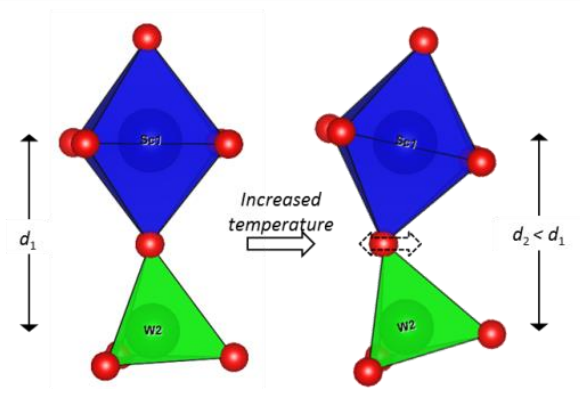

Figure 1: A) Crystal structure of $\mathrm{Sc}_{2}\left(\mathrm{WO}_{4}\right)_{3}$. Oxygen atoms are shown in red, the $\mathrm{ScO}_{6}$ octahedra are represented in blue, while the $\mathrm{W}(1) \mathrm{O}_{4}$ and $\mathrm{W}(2) \mathrm{O}_{4}$ tetrahedra are shown in dark yellow and green, respectively. B) Example of how anharmonic thermal vibration of the bridging oxygen may lead to a tilt between the polyhedral groups resulting in a decrease of the average Sc-W interatomic distances.

\section{Experimental}

Polycrystalline $\mathrm{Sc}_{2}\left(\mathrm{WO}_{4}\right)_{3}$ was prepared via a standard solid state route in air from the constituent oxides. Stoichiometric quantities of $\mathrm{Sc}_{2} \mathrm{O}_{3}(\mathrm{~s})$ and $\mathrm{WO}_{3}(\mathrm{~s})$ were thoroughly mixed, ground and heated in a small cylindrical alumina crucible at 6 ${ }^{\circ} \mathrm{C} / \mathrm{min}$ to $1000{ }^{\circ} \mathrm{C}$, held for 12 hours, followed by regrinding and another 12 hour treatment at $1200{ }^{\circ} \mathrm{C}$. Electrodes were prepared by mixing 80:10:10 wt\% $\mathrm{Sc}_{2}\left(\mathrm{WO}_{4}\right)_{3}$ : carbon black (Timcal C65): polyvinylidene difluoride (PVDF, MTI corporation), with subsequent addition of a minimum amount of n-methyl-2-pyrrolidone solvent in order to make a thick slurry. The slurry was left to stir vigorously overnight before being cast in a $200 \mu \mathrm{m}$ thick layer on a Cu substrate. The cast slurry or electrode was dried in a vacuum oven at $80{ }^{\circ} \mathrm{C}$ overnight followed by pressing at $100 \mathrm{kN}$ for one hour in a hydraulic press. The electrode was then dried for a minimum of two hours in a vacuum oven before being transferred to an Ar-filled glovebox. Here, electrodes of $13 \mathrm{~mm}$ in diameter were punched out and used in the construction of half-cells versus Na. A few drops of electrolyte, $1 \mathrm{M} \mathrm{NaPF}_{6}$ in ethylene carbonate (EC) and dimethyl carbonate (DMC) or propylene carbonate (PC), were added to a glassfibre separator which was placed between the electrode and a thin sheet of $\mathrm{Na}$ metal, before sealing the coin cell.

A range of $\mathrm{Sc}_{2}\left(\mathrm{WO}_{4}\right)_{3}$ samples, with $0 \%$ (blank electrode mixture), $25 \%, 50 \%, 75 \%$ and $100 \%$ of the total capacity density versus $\mathrm{Na}$, were prepared via discharge in an electrochemical cell using a rate of $10 \mathrm{~mA} / \mathrm{g}$ with a Neware battery tester. The capacity or energy density, $C$, of the material was determined from a complete discharge curve to $0.01 \mathrm{~V}$ by Faraday's law of electrolysis, $C=I t / m=F Z / M$, where, $I$ is the applied current, $t$ is the time, $m$ is the mass of the electrode material, $F$ is Faraday's constant, $Z$ is the amount of charge transferred and $M$ is the molar mass of the material. The total capacity is proportional to the maximum theoretical amount of cations that can be transferred to the electrode. Based on this, the time required for partial discharge to $25 \%$, $50 \%$ and $75 \%$ of the total capacity was calculated. Upon reaching the desired state of discharge, the coin cells were immediately transferred to the glovebox and the electrode extracted to minimize any relaxation phenomena. The electrode was washed with DMC to remove excess electrolyte and left to dry. The dry extracted electrode powders were either packed in $0.5 \mathrm{~mm}$ diameter quartz capillaries and sealed under Ar or used as-made.

The crystal structure at room temperature and the structural evolution above room temperature were investigated by high resolution synchrotron PXRD. The diffraction experiments were carried out at the powder diffraction beamline at the Australian Synchrotron. ${ }^{7}$ Data were collected on samples in capillaries using a nominal beam energy of $18 \mathrm{keV}$, a beam size of $3.00 \times 1.15 \mathrm{~mm}$ and a Mythen position sensitive silicon microstrip detector. The exact wavelength was determined to be $0.68727(1) \AA$ using the NIST SRM LaB $_{6} 660 \mathrm{~b}$. Data were measured at two different detector positions with an exposure time of 5 minutes per position and subsequently merged into one diffraction pattern using PDViPeR. ${ }^{8}$ In the VT-PXRD measurements, the sample capillaries were heated using a hot air blower. Measurements were carried out at selected temperatures in the range $50-850{ }^{\circ} \mathrm{C}$ on the blank sample and in the range $50-750{ }^{\circ} \mathrm{C}$ on the $50 \%$ and $75 \% \mathrm{Na}$-containing samples. Temperature ramping rates of $10{ }^{\circ} \mathrm{C} / \mathrm{min}$ during heating and $50 \mathrm{~K} / \mathrm{min}$ during cooling were used and a settling time of 30 seconds was allowed before commencing the data acquisition. Note the short settling time was used due to the size of sample and its location above the blower. Low temperature PXRD data were collected on a Bruker D8 Advance diffractometer using Mo K $\alpha$ radiation. An Oxford Cryostream was used to cool/heat the capillaries with a ramp rate of $20{ }^{\circ} \mathrm{C} / \mathrm{h}$ between $-173{ }^{\circ} \mathrm{C}$ and $173{ }^{\circ} \mathrm{C}$ with a data collection time of 20 minutes over an angular range of $4 \leq 2 \theta \leq$ $50^{\circ}$.

X-ray absorption spectroscopy (XAS) experiments were also performed on the XAS beamline at the Australian Synchrotron. ${ }^{9}$ The XAS spectra were measured on the dry electrode material on a $\mathrm{Cu}$ substrate around the tungsten L3edge ( 10207 eV) using $\mathrm{Sc}_{2}\left(\mathrm{WO}_{4}\right)_{3}$ as $\mathrm{W}(\mathrm{VI})$ and $\mathrm{WO}_{2}$ as $\mathrm{W}(\mathrm{IV})$ references. The XAS data was processed using the ATHENA software of the Demeter software package. ${ }^{10}$ 
Quantitative structural information were extracted by performing Rietveld refinements of structural models with the PXRD data using the Fullprof Suite software package. ${ }^{11}$ The refinements were carried out based on the orthorhombic $\mathrm{Sc}_{2}\left(\mathrm{WO}_{4}\right)_{3}$ structure in space group $P$ nca, ${ }^{6}$ illustrated in Figure 1(A) using VESTA software. ${ }^{12}$ An isotropic independent atom model approach was employed, with atomic positions and isotropic atomic displacement parameters being refined individually for each atom. ${ }^{5}$ Note $\mathrm{Na}$ was not modelled in the structure. Background, scale factor, and unit cell parameters were refined with the background being described by a linear interpolation between a set of background points of refinable intensity. The peak profiles were modeled using the Thompson-Cox-Hastings formulation of the pseudo-Voigt function. The instrumental contribution to the total peak broadening was determined by Rietveld analysis of a NIST LaB 6 $660 \mathrm{~b}$ line profile standard and corrected for in the refinements. The residual broadening was described by refinement of an anisotropic microstrain model. ${ }^{13}$ In certain VT-PXRD experiments, impurities of $\mathrm{WO}_{3}(\mathrm{Pm}-3 \mathrm{~m}$ and $\mathrm{P} 4 / \mathrm{ncc})$ and $\mathrm{WO}_{2}\left(P 12_{1} / c 1\right)$, were also identified and modelled. ${ }^{14-16}$ The weight fraction, $W$, of phase $i$ was calculated from the refined parameters by the formula, $W_{\mathrm{i}}=\left[S_{\mathrm{i}} Z_{\mathrm{i}} M_{\mathrm{i}} V_{\mathrm{i}}\right] / \operatorname{sum}(\mathrm{j})\left[S_{\mathrm{j}} Z_{\mathrm{j}} M_{\mathrm{j}} V_{\mathrm{j}}\right]$, where $S$ is the scale factor, $Z$ is the formula units in the unit cell, $M$ is formula unit mass, and $V$ is the unit cell volume.

\section{Results and discussion}

\section{Electrochemical discharge}

Initial structural characterization of the phase pure $\mathrm{Sc}_{2}\left(\mathrm{WO}_{4}\right)_{3}$ as-synthesized powder can be found in the supporting information, Figure S1. Figure 2 shows the discharge curves for $\mathrm{Sc}_{2}\left(\mathrm{WO}_{4}\right)_{3}$ versus $\mathrm{Na}$ during electrochemical discharge of the half-cell at a current rate of $10 \mathrm{~mA} / \mathrm{g}$. The $25 \%, 75 \%$ and $100 \%$ curves share very similar features with a subtly different $50 \%$ curve. Considering only charge compensation by reduction of tungsten from $\mathrm{W}^{6+}$ to $\mathrm{W}^{4+}$, this in theory allows up to six $\mathrm{Na}^{+}$ ions per formula unit of $\mathrm{Sc}_{2}\left(\mathrm{WO}_{4}\right)_{3}$ before tungsten turns metallic. A capacity of $204 \mathrm{mAh} / \mathrm{g}$ is found which is equivalent to $6.33 \mathrm{Na}^{+}$ions per formula unit or $100 \%$ discharged and four other states were prepared corresponding to $0 \%, 25 \%, 50 \%$, $75 \%$ of this capacity.

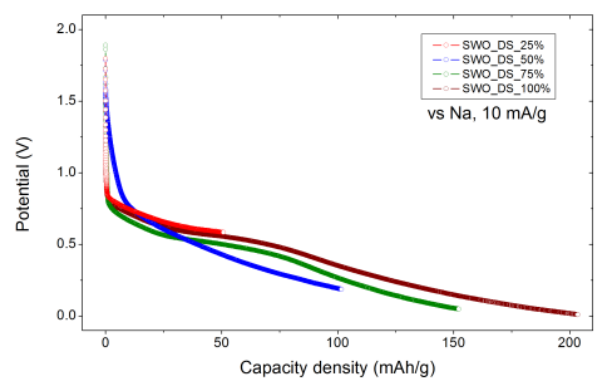

Figure 2: Discharge curves at $10 \mathrm{~mA} / \mathrm{g}$ of $\mathrm{Sc}_{2}\left(\mathrm{WO}_{4}\right)_{3}$ versus $\mathrm{Na} / \mathrm{Na}^{+}$to various degrees of discharge. Slight variations in profiles are due to electrode loading.
In terms of the reactions that can occur to produce this capacity, they include the formation of a solid electrolyte interface layer, ${ }^{17}$ side-reactions in the electrochemical cell, intercalation into $\mathrm{Sc}_{2}\left(\mathrm{WO}_{4}\right)_{3}$ via either a solid solution or two phase mechanism, conversion reactions of $\mathrm{Sc}_{2}\left(\mathrm{WO}_{4}\right)_{3}$ with $\mathrm{Na}$ and combinations of these reactions. The insulating nature of $\mathrm{Sc}_{2}\left(\mathrm{WO}_{4}\right)_{3}$ may mean that interaction with $\mathrm{Na}$ past the surface layer or in the bulk may be challenging or kinetically limited.

XAS measurements were carried out on extracted $\mathrm{Sc}_{2}\left(\mathrm{WO}_{4}\right)_{3}$ electrodes discharged to various states to determine the bulk change in $\mathrm{W}$ oxidation state and provide another indication of the interaction of $\mathrm{Na}$ with the electrode. The position of the absorption edge is known to shift to higher energies with increasing formal valence of the absorber. This is due to the reduction in the nucleus screening resulting in an increased binding energy of the deeper core level electrons. ${ }^{18,} 19$ The spectra were recorded at the tungsten L3-edge $(\sim 10207 \mathrm{eV})$ using $0 \% \mathrm{Sc}_{2}\left(\mathrm{WO}_{4}\right)_{3}$ as $\mathrm{W}(\mathrm{VI})$ and $\mathrm{WO}_{2}$ as $\mathrm{W}(\mathrm{IV})$ references. The background normalized near-edge regions of the recorded spectra of the samples and references are shown in Figure 3(A). The data show a clear variation in edge position, absorption intensity, and in the fine structure at energies above the absorption edge. The edge positions were determined from the first derivative of the XAS spectra shown in Figure $3(B)$ and average tungsten oxidation states estimated from the edge energies by linear extrapolation between the edge energies of the references with known oxidation states. Figure 4 shows the decrease in the estimated mean tungsten oxidation state as function of discharge state of the electrode.
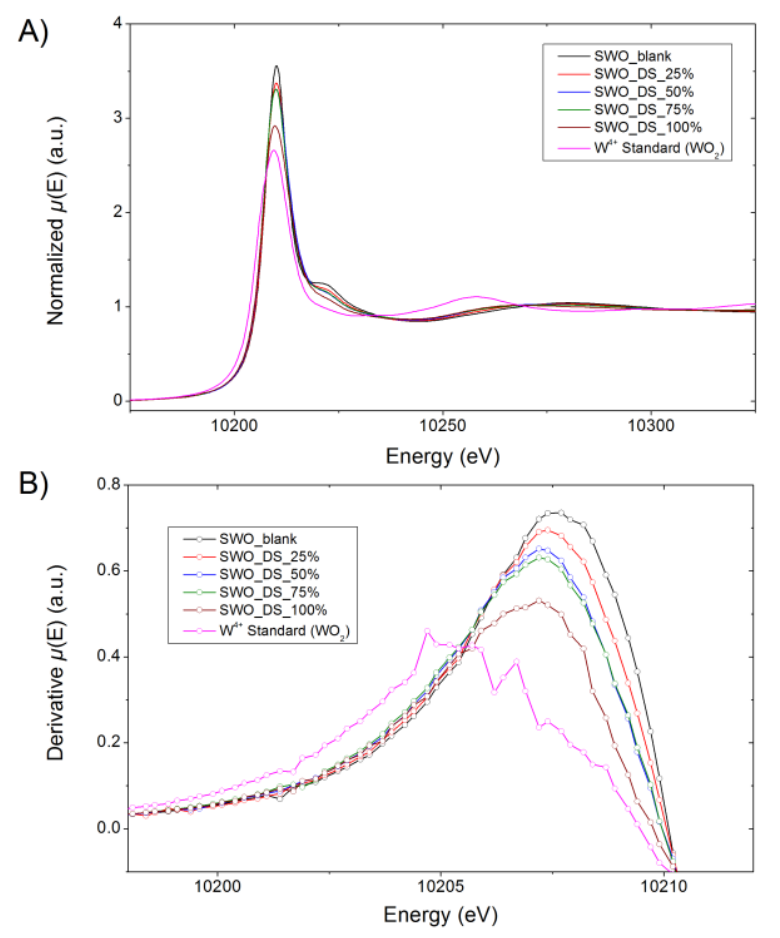

Figure 3: A) Normalized X-ray absorption spectra recorded around the tungsten $\mathrm{L} 3$ edge for $\mathrm{Sc}_{2}\left(\mathrm{WO}_{4}\right)_{3}$ discharged versus $\mathrm{Na}$ to various states. B) First derivative of the spectra, illustrating the shift in edge energy. 


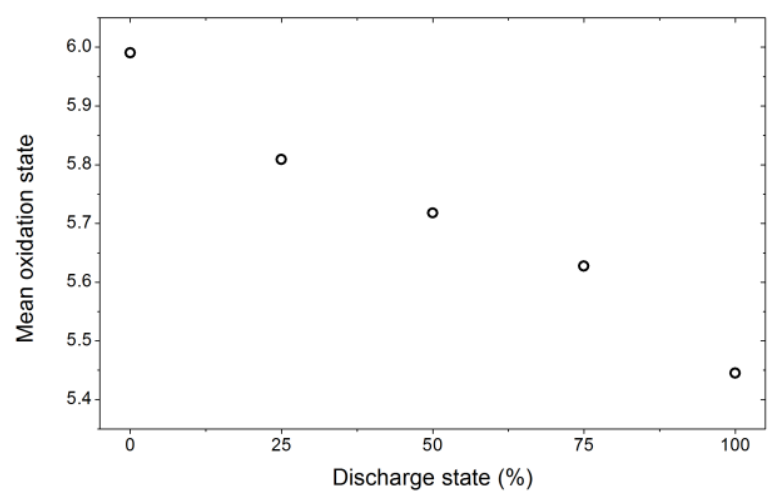

Figure 4: Estimated average tungsten oxidation states found by linear extrapolation between the edge energies of $\mathrm{W}(\mathrm{VI})$ in $\mathrm{Sc}_{2}\left(\mathrm{WO}_{4}\right)_{3}$ and a W(IV) in $\mathrm{WO}_{2}$.

A mean oxidation state of $\sim 5.45$ is estimated for the $100 \%$ discharged electrode and equates to charge compensation for $\sim 1.7 \mathrm{Na}^{+}$ions per formula unit and a total capacity of $\sim 54$ $\mathrm{mAh} / \mathrm{g}$. The discrepancy between the XAS-determined capacity and the capacity from the electrochemical data $(204 \mathrm{mAh} / \mathrm{g})$ may be explained by reaction of $\mathrm{Na}^{+}$into the carbon component of the electrode mixture and/or by the formation of a solid electrolyte interface (SEI) layer, which is not accounted for by the XAS data. In any case, the oxidation state change is observed for the discharged states range from 0.6 to $1.7 \mathrm{Na}^{+}$ions per formula unit.

\section{Room temperature structure}

Figure 5(A-E) show high resolution synchrotron PXRD patterns and Rietveld refined models of extracted $\mathrm{Sc}_{2}\left(\mathrm{WO}_{4}\right)_{3}$ electrodes discharged to different states versus $\mathrm{Na} / \mathrm{Na}^{+}$. The Rietveld analysis of the data reveals the blank $\mathrm{Sc}_{2}\left(\mathrm{WO}_{4}\right)_{3}$ to be phase pure, as expected from the simple mixture of the powder with electrode components, PVDF and carbon black. The refined room temperature unit cell parameters, $a=9.6708$ (1) $\AA, b=$ 13.3207(1) $\AA$ and $c=9.5793(1) \AA$ are in good agreement with the ambient condition values reported in literature and the assynthesized powder-only values (see supporting information, Figure S1). ${ }^{5}$

Rietveld refinement of the $25 \%, 50 \%, 75 \%$ and $100 \%$ discharged samples based on the $\mathrm{Sc}_{2}\left(\mathrm{WO}_{4}\right)_{3}$ structure in the space group Pnca alone fully describes the data and thus reveals no additional crystalline phases to be formed during discharge. However, a substantial decrease in crystallinity with discharge is observed from the gradual decrease in the signal to background ratio as illustrated for three of the main Bragg peaks from $\mathrm{Sc}_{2}\left(\mathrm{WO}_{4}\right)_{3}$ in Figure 6(A). The concurrent increase in background due to the emergence of broad peaks originating from the scattering from the amorphous or nanoscale phase(s) is illustrated in Figure 6(B).

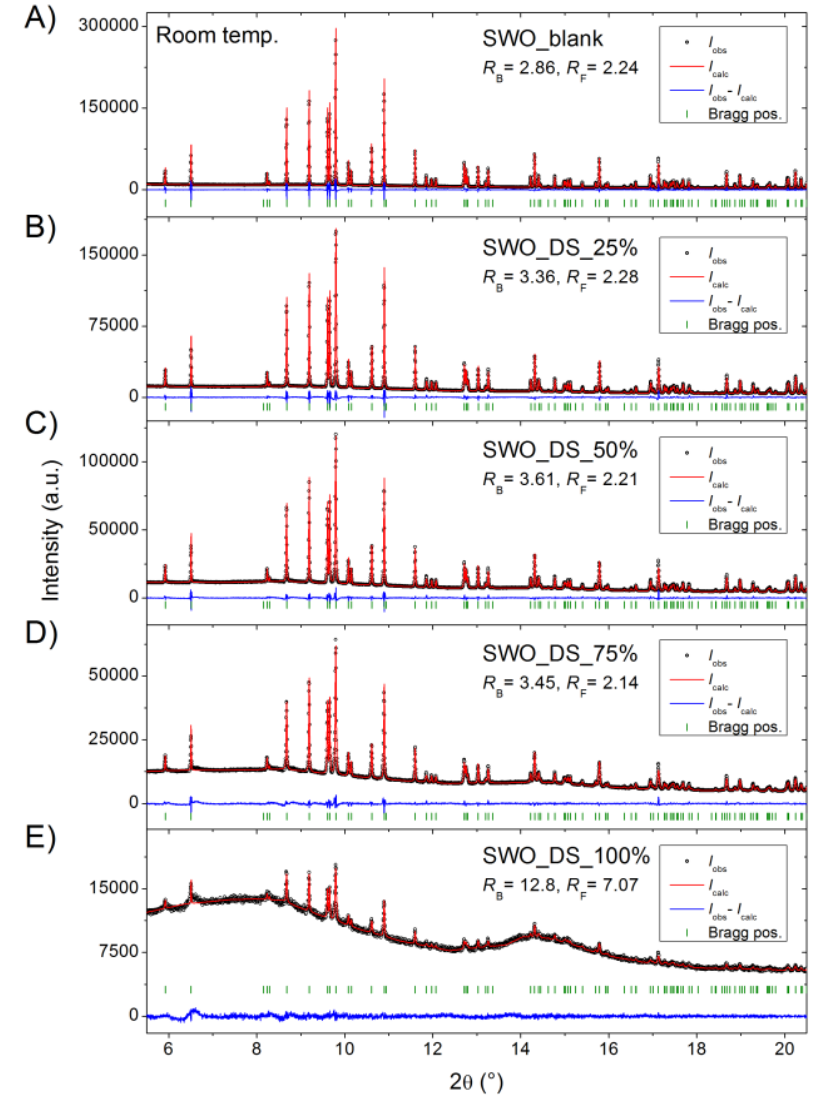

Figure 5: Selected regions of the room temperature PXRD patterns of A) $\mathrm{Sc}_{2}\left(\mathrm{WO}_{4}\right)_{3}$ electrode, SWO_blank, B) $25 \%$ discharged vs $\mathrm{Na}$ (SWO_DS_25\%), C) 50\% discharged vs $\mathrm{Na}$ (SWO_DS_50\%), D) 75\% discharged vs $\mathrm{Na}$ (SWO_DS_75\%) and E) $100 \%$ discharged vs $\mathrm{Na}$ (SWO_DS_100\%) modeled by the Rietveld method in the space group Pnca.
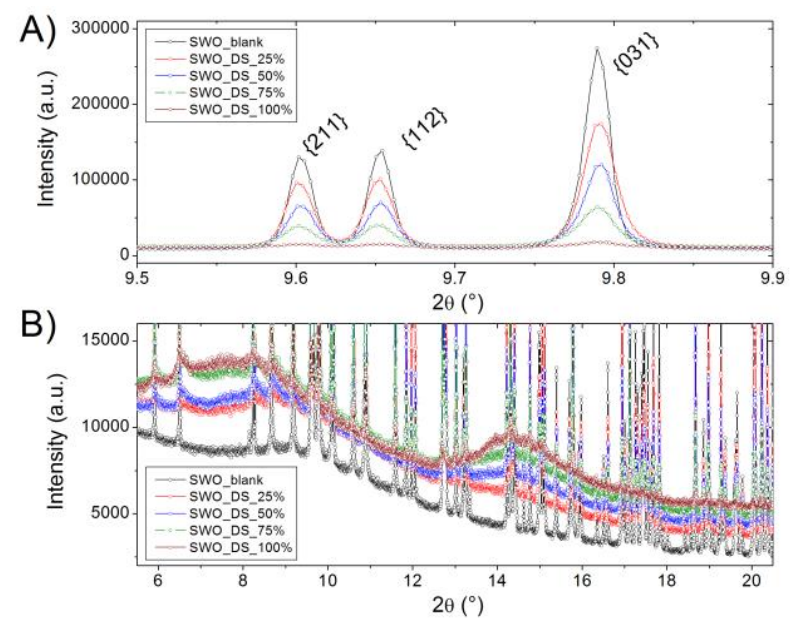

Figure 6: Selected $2 \theta$ region of high resolution PXRD patterns of $\mathrm{Sc}_{2}\left(\mathrm{WO}_{4}\right)_{3}$ discharged to different states versus $\mathrm{Na} / \mathrm{Na}^{+}$. The decrease in crystallinity and amorphization of the sample with discharge is evident from A) the decrease in Bragg peak intensity to background ratio and $B$ ) the emergence of characteristic broad peaks from the amorphous phase. 
The refined lattice parameters as function of tungsten oxidation state determined from XAS (Figure 4) are plotted in Figure $7(A)$. In many materials, accommodation of intercalated ions in the structure leads to a variation of the unit cell dimensions. ${ }^{20-22}$ However, no significant changes in the refined lattice parameters are observed. Detailed analysis of the diffraction patterns reveals a gradual broadening of the Bragg peaks with discharge which can be attributed to either a reduction in size of the coherently scattering crystalline domains or an induced microstrain in the structure. Note defect structures could also be a cause of the broadening noted, but here microstrain appears to best model these data. Peak profile analysis using an isotropic size broadening model did not yield a satisfactory fit to the data and simultaneous refinement of isotropic microstrain parameters did not improve the model significantly. Instead, an anisotropic microstrain model was employed. Figure $7(B)$ shows the refined Stokes-Wilson apparent microstrain as function of discharge. A substantial increase in local lattice distortions in the crystalline phase along all three axes is observed with the insertion. The absolute increase in microstrain varies between the three axes but similar trends are observed. The total increase in the refined Stokes-Wilson apparent microstrain from $\mathrm{Sc}_{2} \mathrm{~W}_{3} \mathrm{O}_{12}$ blank or $0 \%$ to $100 \%$ discharge is $171 \%, 198 \%$ and $160 \%$ along the $h 00, O k O$ and $00 /$ directions, respectively. The microstrain increases in a monotonous fashion along all three directions except for an apparent stagnation between $25 \%$ and $50 \%$ discharge where only a slight change is observed. The observed distortion of the lattice via microstrain and apparent breakdown of long range order is an indication of reactions between the $\mathrm{Sc}_{2}\left(\mathrm{WO}_{4}\right)_{3}$ phase and the discharge process rather than solely surface reactions or SEI formation.

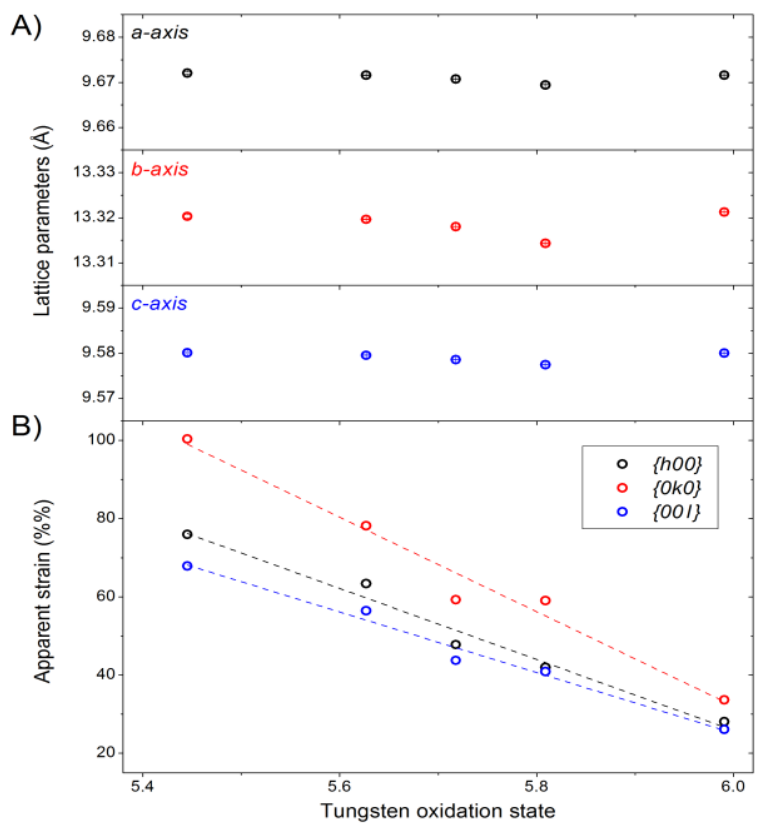

Figure 7: A) Refined unit cell parameters as function of discharge state. B) Refined anisotropic Stokes-Wilson apparent strain as function of tungsten oxidation state.
It should be noted that the overall W oxidation state changes with discharge but the lattice parameters show minimal change. This is speculatively a result of secondary amorphous or nano-crystalline phases forming (correlated to the loss of the $\mathrm{Sc}_{2}\left(\mathrm{WO}_{4}\right)$ reflection intensities or $\mathrm{Sc}_{2}\left(\mathrm{WO}_{4}\right)$ phase) that feature a lower $\mathrm{W}$ oxidation state. Therefore the remaining $\mathrm{Sc}_{2}\left(\mathrm{WO}_{4}\right)$ does not shows change in lattice parameter. The XAS measurements are of the bulk electrode, amorphous and crystalline components while the XRD measurements in this case are sensitive to the crystalline phase.

These results indicate a few possible reaction mechanisms, two of which are the conversion-type reaction and amorphization or a two-phase reaction. In the two-phase reaction, a second phase forms with discharge most likely on the surface of the grains, generating nanosized (possibly amorphous) shells which appear as broad features in the background and this in turn leads to a reduction in the reflection intensity from the crystalline $\mathrm{Sc}_{2}\left(\mathrm{WO}_{4}\right)_{3}$ phase and a slight broadening as the grain size is reduced due to the shell formation. In any case, both the amorphization and two-phase core-shell insertion mechanisms, the question of the subsequent structural evolution is of interest.

In the discharge process, the interaction of the $\mathrm{Sc}_{2}\left(\mathrm{WO}_{4}\right)$ electrode with the $\mathrm{Na}^{+}$can be quite complex as discussed above, ranging from intercalation, conversion reactions or predominantly surface reactions/accumulation. The exact nature of the interaction is slated for future work. Analysis was undertaken on extracted electrodes at room temperature to see if any insertion occurred. Fourier maps or refinements did not indicate any localised $\mathrm{Na}$ sites but this does not preclude some $\mathrm{Na}+$ insertion in a disordered manner or at concentrations too low for stable refinements in addition to the apparent loss of reflection intensities of $\mathrm{Sc}_{2}\left(\mathrm{WO}_{4}\right)$.

\section{Thermal evolution: $0 \%$ electrode}

Figure $8(\mathrm{~A})$ and $(\mathrm{B})$ show cascaded variable temperature PXRD data from selected $2 \theta$ regions of the $0 \%$ or blank $\mathrm{Sc}_{2}\left(\mathrm{WO}_{4}\right)_{3}$ electrode (containing $\mathrm{Sc}_{2}\left(\mathrm{WO}_{4}\right)_{3}$, PVDF and carbon black). The anisotropic thermal expansion of the material is indicated by the $h k l$-index dependent shifts in Bragg peak positions. Peaks with a predominant $h$ and/or $I$ component shift to higher angles while peaks with a predominant $k$ component shift to lower angles, indicating negative and positive expansion, respectively. 


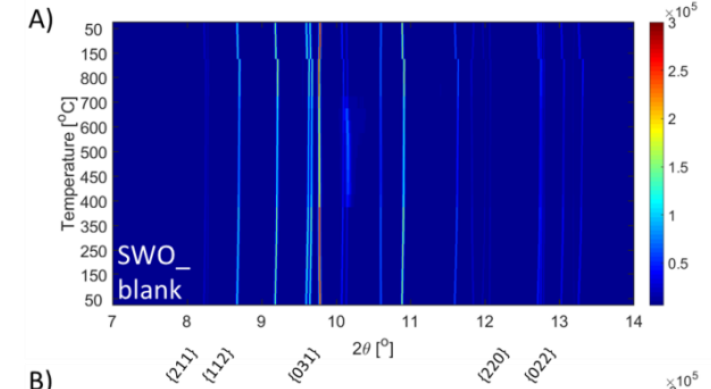

$$
\text { B) }
$$

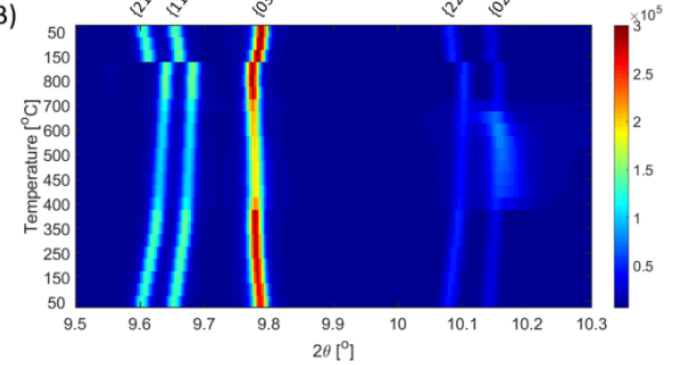

Figure 8: A) Selected $2 \theta$ region of cascaded VT-PXRD data on SWO_blank or $0 \% \mathrm{Sc}_{2}\left(\mathrm{WO}_{4}\right)_{3}$. B) Magnification of a selected region containing some of the main Bragg peaks illustrating the anisotropic expansion with temperature.

In Figure $8(B)$ the emergence of a broad and weak impurity peak at $2 \theta \approx 10.15^{\circ}$ which overlaps with the 220 reflection from the main $\mathrm{Sc}_{2}\left(\mathrm{WO}_{4}\right)_{3}$ phase can be seen when the temperature is increased above $375^{\circ} \mathrm{C}$. Figure $9(\mathrm{~A})$ shows the diffraction pattern obtained at $450{ }^{\circ} \mathrm{C}$ modeled by the Rietveld method. The impurity peaks were attributed to cubic $\mathrm{WO}_{3}$ and modeled in space group $P m-3 m$, as illustrated in the inserts of Figure $9(A)$. Figure $9(B)$ shows the diffraction pattern and Rietveld model of the $850{ }^{\circ} \mathrm{C}$ dataset. Above $700{ }^{\circ} \mathrm{C}$ the $\mathrm{WO}_{3}$ impurity peaks split indicating a phase change but a concurrent decrease in diffraction intensity from the $\mathrm{WO}_{3}$ phase to effectively negligible levels. The best description of the very weak $\mathrm{WO}_{3}$ peaks was achieved with a model based on tetragonal $\mathrm{WO}_{3}$ in space group $\mathrm{P} 4 /$ ncc. Simultaneously with the $\mathrm{WO}_{3}$ peak splitting above $700{ }^{\circ} \mathrm{C}$, several very weak impurity peaks appear which were identified as monoclinic $\mathrm{WO}_{2}$ in space group $P 12_{1} / c 1$. The contribution to the diffraction pattern from the almost negligible amounts of impurities and a single weak peak at $2 \theta \approx 9.55$, which remained unidentified, are illustrated in the inserts of Figure $9(B)$. The evolution in phase composition determined by the Rietveld analysis is illustrated in Figure $10(\mathrm{~A})$ for the $0 \% \mathrm{Sc}_{2}\left(\mathrm{WO}_{4}\right)_{3}$. The $\mathrm{Sc}_{2}\left(\mathrm{WO}_{4}\right)_{3}$ phase remains dominant throughout the entire temperature regime. However, a considerable amount of cubic $\mathrm{WO}_{3}$ is present in the temperature interval $400-700{ }^{\circ} \mathrm{C}$, reaching a maximum of $13.1(2) \%$ at $650{ }^{\circ} \mathrm{C}$. Above $700{ }^{\circ} \mathrm{C}$ minute amounts of tetragonal $\mathrm{WO}_{3}(<0.2 \%), \mathrm{WO}_{2}(<0.6 \%)$, and an additional unknown impurity phase were present. Upon cooling back to $50{ }^{\circ} \mathrm{C}$, the impurity peaks disappear and the peaks from the main $\mathrm{Sc}_{2}\left(\mathrm{WO}_{4}\right)_{3}$ phase return to their original intensities indicating a recrystallization and thermal reversibility of the material.

Interestingly, the presence of $\mathrm{WO}_{3}$ was not observed in earlier thermal studies of pure $\mathrm{Sc}_{2}\left(\mathrm{WO}_{4}\right)_{3}$ powders and its presence and generation may be due to a number of factors. These include, reactions with the quartz capillary housing the powder, interaction and subsequent reaction with the PVDF or carbon components of the electrode. Noting that PVDF melts at $177{ }^{\circ} \mathrm{C}$ and carbon black based on Timcal's MSDS decomposes at " $>400{ }^{\circ} \mathrm{C}$ " the generation of secondary phases are most likely attributed to reactions with these components. Furthermore, the presence of reduced $\mathrm{WO}_{2}$ at higher temperatures could be driven by the slightly reducing conditions generated by decomposing carbon black. Thermogravimetric (TGA) data, see supporting information Figure S2, of carbon black, PVDF, and PVDF/carbon black under Ar flow shows significant mass loss from about $425^{\circ} \mathrm{C}$, close to the appearance of $\mathrm{WO}_{3}$ in the variable temperature synchrotron XRD data of $\mathrm{Sc}_{2}\left(\mathrm{WO}_{4}\right)_{3} / \mathrm{PVDF} /$ carbon black. The generation of $\mathrm{WO}_{3}$ in the $\mathrm{Sc}_{2}\left(\mathrm{WO}_{4}\right)_{3}$ electrode implies that there is loss of $\mathrm{W}$, at least on the surface of $\mathrm{Sc}_{2}\left(\mathrm{WO}_{4}\right)_{3}$ particles. This could occur by the generation of $\mathrm{W}$ vacancies on these sites and some surface re-arrangement or by the Sc containing component forming other compounds that are small in size (nanoscale) or amorphous and therefore not directly observed by XRD. The generation of $\mathrm{WO}_{3}$ at above 375 ${ }^{\circ} \mathrm{C}$ is important as this temperature appears to instigate the changes observed in the further discharged electrodes.

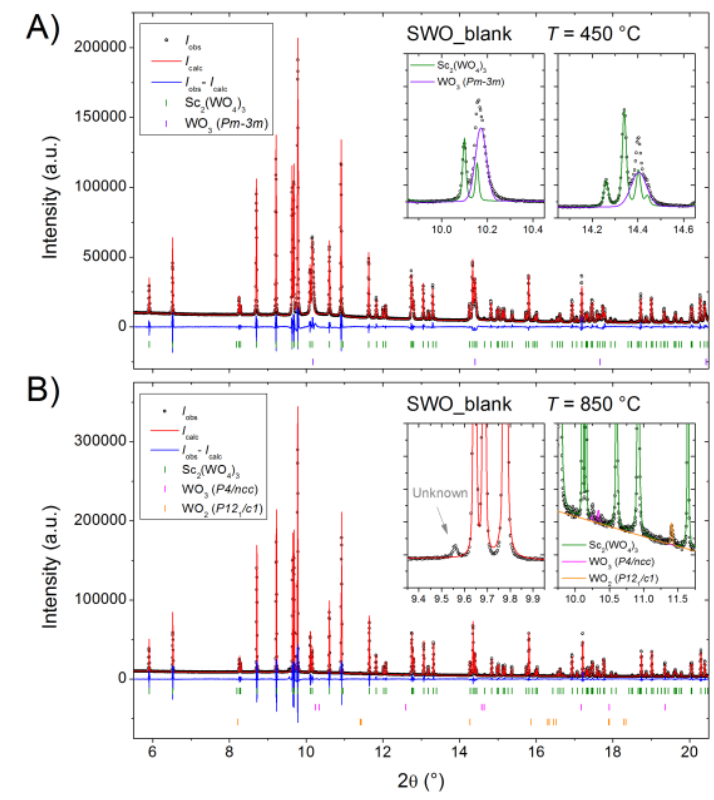

Figure 9: Diffraction patterns and Rietveld refined models of the blank or $0 \% \mathrm{Sc}_{2}\left(\mathrm{WO}_{4}\right)_{3}$ electrode at A) $450{ }^{\circ} \mathrm{C}$ and $\left.\mathrm{B}\right) 850{ }^{\circ} \mathrm{C}$. 


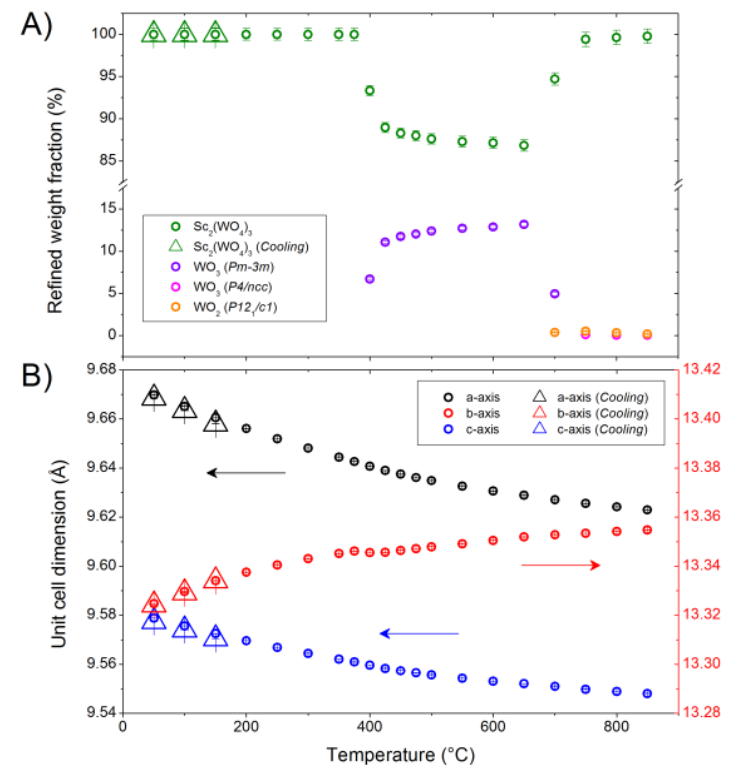

capillary initiating the reactions observed. Such an environment appears advantageous for the generation of new phases as discussed below.

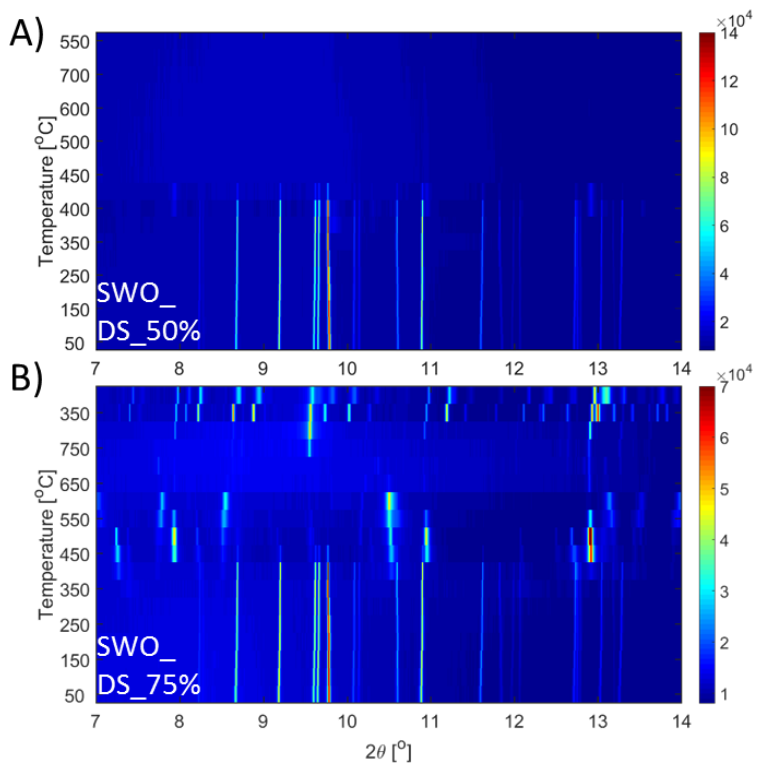

Figure 10: A) Refined weight fractions illustrating the phase composition as function of temperature for $0 \% \mathrm{Sc}_{2}\left(\mathrm{WO}_{4}\right)_{3}$ and B) refined unit cell parameters as function of temperature.

The refined unit cell parameters of $0 \% \mathrm{Sc}_{2}\left(\mathrm{WO}_{4}\right)_{3}$ are plotted in Figure 10(B). An anisotropic thermal expansion behavior with negative expansion along the crystallographic $a$ - and $c$-axes and positive expansion along the $b$-axis is observed. The negative contribution from the $a$ - and $c$-axes outweighs the expansion along $b$ leading to an overall contraction in unit cell volume with temperature within the measured temperature span. A total volume reduction of $0.6 \%$ is observed in the investigated temperature range, which correlates well with previously reported data, see supporting information Figure S3 for a direct comparison. ${ }^{5}$

\section{Thermal evolution: $\mathbf{5 0 \%}$ and $\mathbf{7 5 \%}$ discharged $\mathrm{Sc}_{2}\left(\mathrm{WO}_{4}\right)_{3}$}

Selected samples were used for similar VT-PXRD studies in the temperature range $50-750{ }^{\circ} \mathrm{C}$. Cascade VT-PXRD patterns of $50 \%$ and $75 \%$ discharged $\mathrm{Sc}_{2}\left(\mathrm{WO}_{4}\right)_{3}$ are shown in Figure 11(A) and (B), respectively. Notably, the data show a clear destabilizing effect of the discharge process, with various phase transitions taking place when heating the samples above $375^{\circ} \mathrm{C}$ and pronounced amorphization occurring above $450{ }^{\circ} \mathrm{C}$. The temperature corresponds to the mass loss observed in the TGA data suggesting a molten/gaseous environment in the

Figure 11: Selected $2 \theta$ region of cascaded VT-PXRD data on A) $50 \%$ discharged and B) $75 \%$ discharged electrodes.

In the 50\% discharged sample, additional strong peaks emerge when heating the sample above $375^{\circ} \mathrm{C}$. Figure 12 (A) shows the diffraction pattern and refined model of the $50 \%$ discharged electrode at $425^{\circ} \mathrm{C}$ with the additional peaks indicated by grey arrows in the insert. The blue curve, illustrating the difference between the measured diffracted intensity and the refined model, can effectively act as a diffraction pattern of the additional crystalline phases. The limited number of distinct and strong peaks and the similarity in peak profiles (width) could indicate that these peaks arise from a single phase. However, attempts at identifying the phase by indexing the Bragg peaks based on a number of the most common and probable structures containing the constituent elements and by brute force database searches were unsuccessful. The amount of the unknown phase increases from 375 to $425^{\circ} \mathrm{C}$ but above $450{ }^{\circ} \mathrm{C}$ a complete amorphization of the $\mathrm{Sc}_{2}\left(\mathrm{WO}_{4}\right)_{3}$ phase occurs and only a minute amount of the unidentified phase remains as illustrated in Figure 12(B). Continued heating to $750{ }^{\circ} \mathrm{C}$ and subsequent cooling to $550{ }^{\circ} \mathrm{C}$ of the $50 \%$ discharged sample did not induce formation of any new crystalline phases or recrystallization of the $\mathrm{Sc}_{2}\left(\mathrm{WO}_{4}\right)_{3}$ phase. 


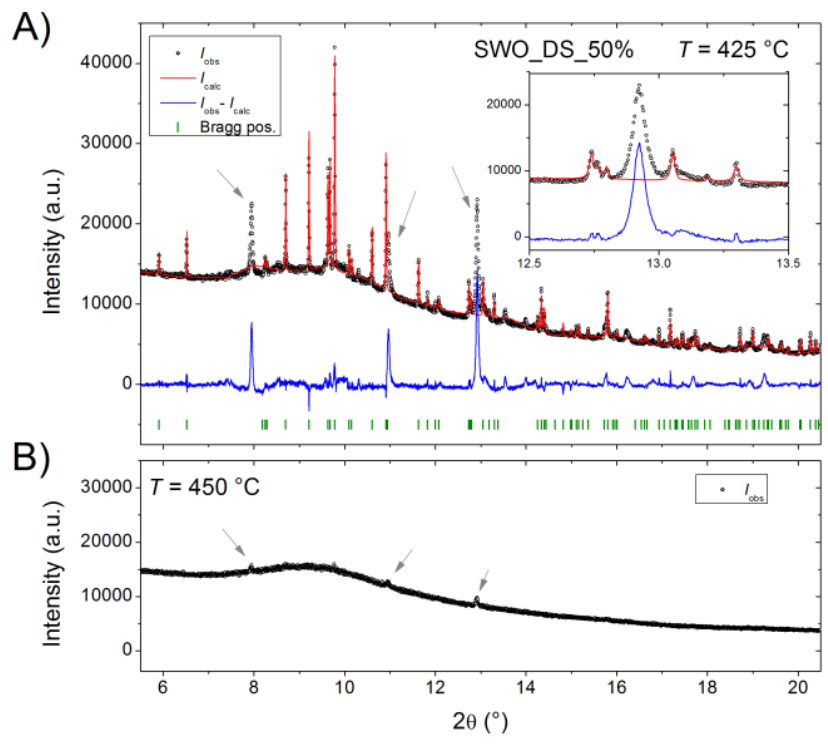

Figure 12: Diffraction pattern and Rietveld refined model of $50 \%$ discharged at A) $425^{\circ} \mathrm{C}$ and B) $450{ }^{\circ} \mathrm{C}$.

Figure 13 shows the diffraction patterns of the $75 \%$ discharged electrode at a number of selected temperatures. This sample exhibits a much more complex structural and compositional behavior with temperature compared to the $50 \%$ discharged sample. Figure 13(A) shows the diffraction pattern and refined model of $\mathrm{Sc}_{2}\left(\mathrm{WO}_{4}\right)_{3}$ at $400{ }^{\circ} \mathrm{C}$, with the initial appearance of additional peaks indicated by grey arrows. At $500{ }^{\circ} \mathrm{C}$ the $\mathrm{Sc}_{2}\left(\mathrm{WO}_{4}\right)_{3}$ phase has disappeared completely and instead a combination of several different crystalline phases has formed as seen in Figure 13(B). Note, the peak profiles of all peaks are not the same which suggest at least two phase(s) are present in the sample at this stage. From 500 to $600{ }^{\circ} \mathrm{C}$ another phase transition takes place. The number of peaks and their intensity is reduced as seen in Figure 13(C). Along with the similarity of the peak profiles, this could indicate the formation of a single unidentified crystalline phase occurring at around $600{ }^{\circ} \mathrm{C}$. At the highest temperatures of $700-750{ }^{\circ} \mathrm{C}$ the sample turns amorphous with only small amounts of crystalline materials remaining, as illustrated in Figure 13(D). Upon cooling, the sample goes through another series of phase transitions but does not at any point return to the $\mathrm{Sc}_{2}\left(\mathrm{WO}_{4}\right)_{3}$ phase. Instead, an intricate combination of several crystalline phases form, as shown in Figure $13(\mathrm{E})$ and $(\mathrm{F})$ for $350{ }^{\circ} \mathrm{C}$ and $150{ }^{\circ} \mathrm{C}$, respectively.
A)

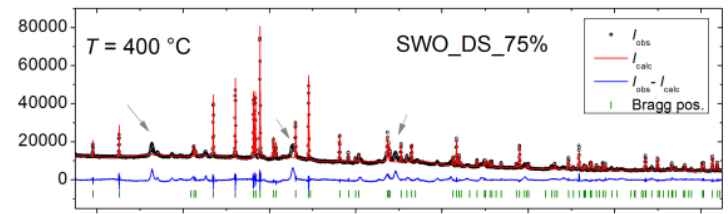

B)

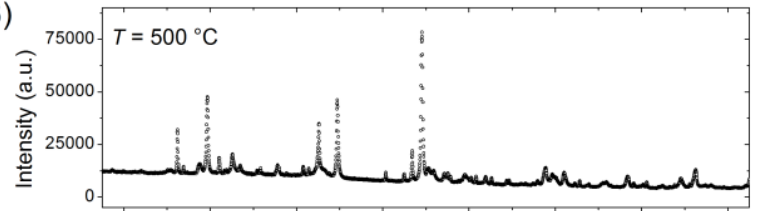

C)

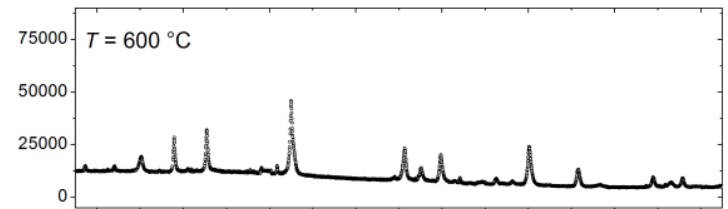

D)

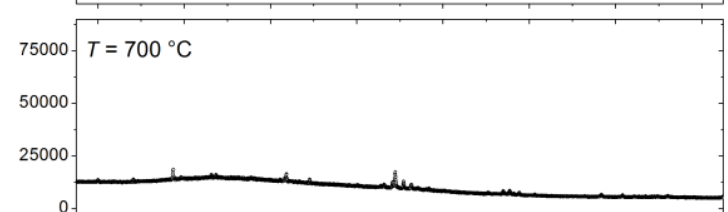

E)

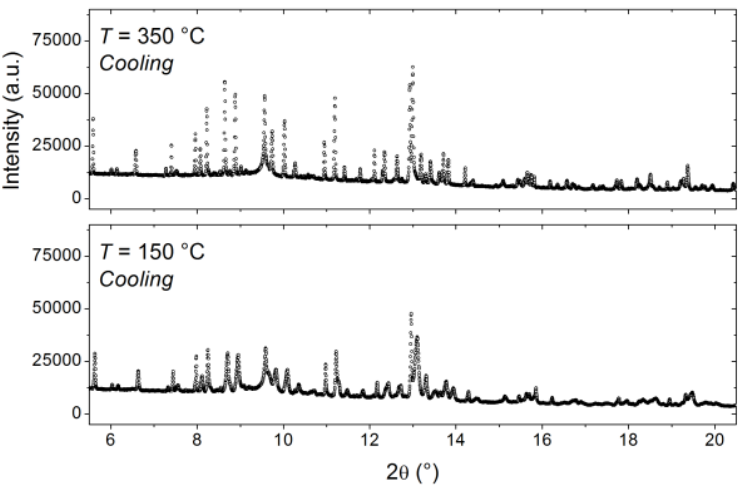

Figure 13: A) Diffraction pattern and Rietveld refined model of $75 \%$ discharged $\mathrm{Sc}_{2}\left(\mathrm{WO}_{4}\right)_{3}$ at $400{ }^{\circ} \mathrm{C}$. B-F) Diffraction patterns of $75 \%$ discharged $\mathrm{Sc}_{2}\left(\mathrm{WO}_{4}\right)_{3}$ at the indicated temperatures.

Identification of the various phases formed in the discharged samples has so far been inconclusive. Upon heating, the samples become a complex combination of numerous phases making peak indexing difficult. Database searches and comparison to simulated diffraction patterns of a large number of suspected phases, including $\mathrm{WO}_{2}, \mathrm{WO}_{3}$ (seven different space groups), $\mathrm{Sc}_{2} \mathrm{O}_{3}$ (two different space groups), $\mathrm{Sc}_{6} \mathrm{WO}_{12}$, Sc (two different space groups), W, $\mathrm{Na}, \mathrm{Na}_{2} \mathrm{O}, \mathrm{Na}_{2} \mathrm{O}_{2}$, $\mathrm{NaO}_{2}, \mathrm{NaO}_{3}$, and several other potential candidates, did not yield any definitive result. Clearly the number of phases formed and the phase transitions observed are unexpected and worthy of future studies.

We note that the $\mathrm{Sc}_{2}\left(\mathrm{WO}_{4}\right)_{3}$ electrode does not form any new unidentified phases upon heating, see Figures 8-10, but when the $\mathrm{Sc}_{2}\left(\mathrm{WO}_{4}\right)_{3}$ electrode is discharged in a $\mathrm{Na}$ half-cell, a new series of phase transitions occur with heating generating new phases that could not be identified in the structural databases. Thus the act of discharging, the reactions that occur and the subsequent heating of these reactions causes new phases to be formed. In order to attempt to describe these new phases, preliminary indexing has been conducted and the results of which are presented in the Supporting Information. The 
complexity of the phase evolution can be seen by the probable number of phases at sample discharge states, see Supporting Information Figures S5 and S6. Further work is required to fully characterise these phases.

Based on the ex situ XRD data, the discharge process amphorsizes, nano-sizes or surface reacts with $\mathrm{Sc}_{2}\left(\mathrm{WO}_{4}\right)_{3}$ component in the electrode as evidenced by the loss in reflection intensities. This reaction then facilitates the generation of new phases during thermal treatment relative to a non-discharged $\mathrm{Sc}_{2}\left(\mathrm{WO}_{4}\right)_{3}$ electrode.

\section{Thermal expansion}

Rietveld refinement of the $\mathrm{Sc}_{2}\left(\mathrm{WO}_{4}\right)_{3}$ structural model in space group Pnca with diffraction patterns from the discharged samples in a range of temperatures was carried out disregarding contributions from the unidentified additional phases. Figure $14(\mathrm{~A})$ shows the refined $\mathrm{Sc}_{2}\left(\mathrm{WO}_{4}\right)_{3}$ scale factors for the three samples normalized by their initial value as a function of temperature. Assuming a constant probed sample volume, the scale factor can be used as a measure of the evolution in sample crystallinity and weight fraction. The $0 \%$ $\mathrm{Sc}_{2}\left(\mathrm{WO}_{4}\right)_{3}$ remains stable from $50-375{ }^{\circ} \mathrm{C}$, above which the formation of various tungsten oxides or reactions with the electrode components causes the amount of $\mathrm{Sc}_{2}\left(\mathrm{WO}_{4}\right)_{3}$ to decrease. Continued heating above $650{ }^{\circ} \mathrm{C}$ leads to an increase in the scale factor indicating partial recrystallization of $\mathrm{Sc}_{2}\left(\mathrm{WO}_{4}\right)_{3}$, which is visually observed in Figure $8(\mathrm{~B})$. Cooling back to $50{ }^{\circ} \mathrm{C}$, the scale factor of this sample returns to its initial value. For the two discharged samples the gradual decrease in scale factor in the $50-375^{\circ} \mathrm{C}$ range correlates with the decrease in crystallinity and above this temperature a complete amorphization or phase-loss takes place.
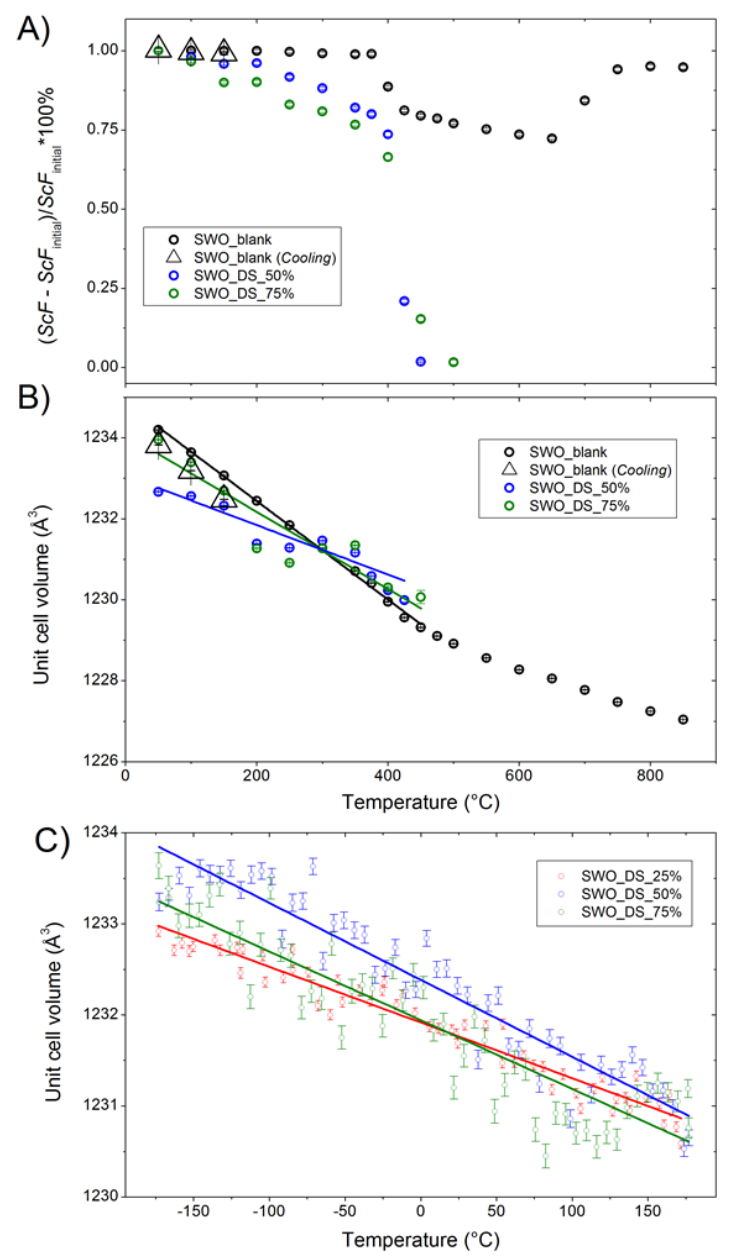

Figure 14: A) Normalized $\mathrm{Sc}_{2}\left(\mathrm{WO}_{4}\right)_{3}$ scale factors as function of temperature (synchrotron). Refined unit cell volume as function of temperature for $B$ ) high temperature synchrotron PXRD data and C) in-house low temperature VT-PXRD data.

The changes in refined unit cell volumes with temperature illustrate a slight influence on the NTE, Figure 14(B). The $0 \%$ $\mathrm{Sc}_{2}\left(\mathrm{WO}_{4}\right)_{3}$ electrode exhibits a continuous decrease in unit cell volume with temperature with a change in slope at about $\sim 400$ ${ }^{\circ} \mathrm{C}$ and the on cooling returns to a slightly lower value, 1233.82(1) $\AA^{3}$, than the initial volume of $1234.20(1) \AA^{3}$ at 50 ${ }^{\circ} \mathrm{C}$. Both the $50 \%$ and $75 \%$ discharged electrode also exhibit NTE below the decomposition temperatures. From about 150 ${ }^{\circ} \mathrm{C}$ to phase loss both the 50 and $75 \%$ discharged electrodes follow essentially the same thermal evolution in unit cell parameters. For the $0 \% \mathrm{Sc}_{2}\left(\mathrm{WO}_{4}\right)_{3}$, the volumetric expansion coefficient, $\alpha_{\mathrm{Vol}}$, was found from a linear fit to the refined values to be $-9.9(1) \cdot 10^{-6} \mathrm{~K}^{-1}$ between $50-450^{\circ} \mathrm{C}$, which is larger than the $-6.5 \cdot 10^{-6} \mathrm{~K}^{-1}$ reported in the lower temperature range 10-450 K,5 presumably due to the interaction with the electrode components. The intrinsic linear thermal expansion coefficient can be estimated as $\alpha_{1}=1 / 3 \quad \alpha_{\mathrm{Vol}}$ which gives $3.3(1) \cdot 10^{-6} \mathrm{~K}^{-1}$. This is smaller than extrinsic value measured by dilatometry of $-5.6 \cdot 10^{-6} \mathrm{~K}^{-1}, 23$ and values in the range of $-6 \cdot 10^{-6}$ $\mathrm{K}^{-1}$ to $-11 \cdot 10^{-6} \mathrm{~K}^{-1}$ reported. ${ }^{5} \mathrm{~A}$ slight NTE dampening effect is observed in the $50 \%$ and $75 \%$ discharged electrodes, where overall volumetric thermal expansion coefficients of $-5.5(6) \cdot 10^{-}$ 
${ }^{6} \mathrm{~K}^{-1}$ for the $50 \%$ discharged and $-7(1) \cdot 10^{-6} \mathrm{~K}^{-1}$ for the $75 \%$ discharged, are obtained between $50-450{ }^{\circ} \mathrm{C}$, noting that this section appears not to be linear.

Low temperature PXRD data were collected to elucidate the volume evolution, Figure 14 (C) and an example dataset shown in Figure S4. Interestingly the low temperature data show no discernable differences in volume evolution between the various discharged electrodes from $-173{ }^{\circ} \mathrm{C}$ to $173{ }^{\circ} \mathrm{C}$, just below the melting the point of PVDF. Table 1 summarizes the thermal expansion coefficients from all PXRD data.

The thermal evolution of the $\mathrm{Sc}_{2}\left(\mathrm{WO}_{4}\right)_{3}$ component at temperatures below $450^{\circ} \mathrm{C}$ show very little change in NTE but the act of discharge in a Na half-cell dramatically influences thermal properties at higher temperatures by inducing the formation of new phases, a new finding for such materials and processes.

Table 1: Axial $\left(\alpha_{\mathrm{a}}, \alpha_{\mathrm{b}}, \alpha_{\mathrm{c}}\right)$ and volumetric $\left(\alpha_{\mathrm{V}_{\mathrm{ol}}}\right)$ thermal expansion coefficients estimated by linear fits to the Rietveld refined values, and estimated intrinsic linear thermal expansion coefficient $\left(\alpha_{1}\right)$. Note there is a noticeably larger spread in data for the low temperature laboratory XRD compared to synchrotron XRD experiments. This is particularly evident at temperatures above $0^{\circ} \mathrm{C}$. Such variation reduces the precision of the thermal expansion coefficients for laboratory XRD.

\begin{tabular}{|c|c|c|c|c|c|c|}
\hline $\begin{array}{l}\mathrm{Sc}_{2}\left(\mathrm{WO}_{4}\right)_{3} \\
\text { electrode Sample }\end{array}$ & & $\begin{array}{l}\alpha_{\mathrm{a}} \\
\times 10^{-6} \mathrm{~K}^{-1}\end{array}$ & $\begin{array}{l}\alpha_{b} \\
\times 10^{-6} \mathrm{~K}^{-1}\end{array}$ & $\begin{array}{l}\alpha_{\mathrm{c}} \\
\times 10^{-6} \mathrm{~K}^{-1}\end{array}$ & $\begin{array}{l}\alpha_{\mathrm{Vol}} \\
\times 10^{-6} \mathrm{~K}^{-1}\end{array}$ & $\begin{array}{l}\alpha_{1} \\
\times 10^{-6} \mathrm{~K}^{-1}\end{array}$ \\
\hline $0 \%$ discharged & Synchr. $\left(50 \rightarrow 450^{\circ} \mathrm{C}\right)$ & $\begin{array}{l}-8.3(1) \\
-\end{array}$ & $\begin{array}{l}4.0(4) \\
-\end{array}$ & $\begin{array}{l}-5.5(1) \\
-\end{array}$ & $\begin{array}{l}-9.9(1) \\
-\end{array}$ & $-3.3(1)$ \\
\hline $25 \%$ discharged & $\operatorname{Lab}\left(-173 \rightarrow 173^{\circ} \mathrm{C}\right)$ & $\begin{array}{l}- \\
-7.5(1)\end{array}$ & $\begin{array}{l}- \\
8.3(1)\end{array}$ & $-5.8(1)$ & $-5.0(2)$ & $-1.7(1)$ \\
\hline $50 \%$ discharged & $\begin{array}{l}\text { Synchr. }\left(50 \rightarrow 450^{\circ} \mathrm{C}\right) \\
\text { Lab }\left(-173 \rightarrow 173^{\circ} \mathrm{C}\right)\end{array}$ & $\begin{array}{l}-7.4(2) \\
-8.6(1) \\
\end{array}$ & $\begin{array}{l}6.8(4) \\
8.4(1)\end{array}$ & $\begin{array}{l}-4.4(2) \\
-6.7(1)\end{array}$ & $\begin{array}{l}-5.5(6) \\
-6.9(3) \\
\end{array}$ & $\begin{array}{l}-1.8(2) \\
-2.3(1)\end{array}$ \\
\hline 75\% discharged & $\begin{array}{l}\text { Synchr. }\left(50 \rightarrow 450^{\circ} \mathrm{C}\right) \\
\text { Lab }\left(-173 \rightarrow 173^{\circ} \mathrm{C}\right)\end{array}$ & $\begin{array}{l}-8.2(4) \\
-8.1(2)\end{array}$ & $\begin{array}{l}5.6(6) \\
8.4(2)\end{array}$ & $\begin{array}{l}-5.1(4) \\
-6.4(2)\end{array}$ & $\begin{array}{l}-7(1) \\
-6.1(4)\end{array}$ & $\begin{array}{l}-2.3(4) \\
-2.0(2)\end{array}$ \\
\hline
\end{tabular}

\section{Conclusions}

Phase pure $\mathrm{Sc}_{2}\left(\mathrm{WO}_{4}\right)_{3}$ was successfully prepared by the solid state synthesis route, and discharged versus $\mathrm{Na}$ to various states in standard coin half-cell batteries. A total discharge capacity or energy density of $204 \mathrm{mAh} / \mathrm{g}$ was found from the complete discharge to $0.01 \mathrm{~V}$ at a rate of $10 \mathrm{~mA} / \mathrm{g}$. Diffraction patterns measured on extracted electrodes, ex situ, reveals a gradual breakdown of long range order and an increase in anisotropic microstrain as function of discharge. XAS revealed a reduction in the $\mathrm{W}$ oxidation state due to charge compensation. The high temperature thermal properties of the $\mathrm{Sc}_{2}\left(\mathrm{WO}_{4}\right)_{3}$ electrode were clearly influenced by the presence of carbon black and PVDF in the electrode mix and shows the generation of $\mathrm{WO}_{3}$ above $375^{\circ} \mathrm{C}$. The $50 \%$ and $75 \%$ discharged electrode show significant changes in phase evolution with temperature, with temperatures above $400{ }^{\circ} \mathrm{C}$ decomposing $\mathrm{Sc}_{2}\left(\mathrm{WO}_{4}\right)_{3}$ and forming new phases, each with their own evolution characteristics. Between $50-400{ }^{\circ} \mathrm{C}$, subtle changes in the NTE of the discharged and undischarged electrode were noted and at low temperature the electrodes show very similar NTE properties. This work shows that using an electrochemical cell to react $\mathrm{Na}$ with $\mathrm{Sc}_{2}\left(\mathrm{WO}_{4}\right)_{3}$, extract the electrodes and observe thermal evolution leads to the generation of new phases and this may be a possible solid state method to explore a significantly larger proportion of reaction and phase space.

\section{Acknowledgements}

We are very grateful to Prof. John Evans (Durham University) for his insightful comments, mentorship throughout this project and use of the department's Bruker D8. Neeraj Sharma would like to thank the Royal Society of Chemistry for the travel funds to visit Durham University under the Researcher Mobility Scheme. This work was financially supported by the Australian Research Council, grants DE160100237 / DP170100269. Henrik L. Andersen is grateful for the financial support received from Innovation Fund Denmark, Green Chemistry for Advanced Materials (GCAM-4107-00008B), Oticon Fonden and Knud Højgaards Fond. Othman K. Al Bahri is grateful to the Ministry of Higher Education (Oman) for funding his undergraduate studies. Foong King Yoong is thanked for his assistance during synchrotron beamtimes. Part of this research was undertaken on the Powder Diffraction and $X$-ray Absorption Spectroscopy beamlines at the Australian Synchrotron, part of the Australian Nuclear Science and Technology Organisation (ANSTO).

\section{Notes and references}

1. M. Armand and J. M. Tarascon, Nature, 2008, 451, 652657.

2. J. B. Goodenough and Y. Kim, Chem. Mater., 2010, 22, 587-603.

3. V. Palomares, P. Serras, I. Villaluenga, K. B. Hueso, J. Carretero-Gonzalez and T. Rojo, Energy Environ. Sci., 2012, 5, 5884-5901.

4. J. C. Pramudita, D. Sehrawat, D. Goonetilleke and N. Sharma, Adv. Energy Mater., 2017, 1602911. 
5. J. S. O. Evans, T. A. Mary and A. W. Sleight, J Solid State Chem, 1998, 137, 148-160.

6. S. C. Abrahams and J. L. Bernstein, The Journal of Chemical Physics, 1966, 45, 2745-2752.

7. K. S. Wallwork, B. J. Kennedy and D. Wang, Aip Conf Proc, 2007, 879, 879-882.

8. http://www.synchrotron.org.au/pdviper

9. C. Glover, J. McKinlay, M. Clift, B. Barg, J. Boldeman, M. Ridgway, G. Foran, R. Garrett, P. Lay and A. Broadbent, $X$ Ray Absorption Fine Structure-XAFS13, 2007, 882, 884886.

10. B. Ravel and M. Newville, J Synchrotron Radiat, 2005, 12, 537-541.

11. J. Rodriguez-Carvajal, Physica B: Condensed Matter, 1993, 192, 55-69.

12. K. Momma and F. Izumi, Journal of Applied Crystallography, 2011, 44, 1272-1276.

13. J. Rodriguez Carvajal, M. T. Fernandez Diaz and J. L. Martinez, J Phys-Condens Mat, 1991, 3, 3215-3234.

14. D. V. Suetin, I. R. Shein and A. L. Ivanovskii, physica status solidi (b), 2011, 248, 2884-2892.

15. T. Vogt, P. M. Woodward and B. A. Hunter, J Solid State Chem, 1999, 144, 209-215.

16. D. J. Palmer and P. G. Dickens, Acta Crystallogr B, 1979, 35, 2199-2201.

17. M. Winter, J. O. Besenhard, M. E. Spahr and P. Novak, Adv Mater, 1998, 10, 725-763.

18. F. Hippert, Neutron and X-ray spectroscopy, Springer, Dordrecht, 2006.

19. S. Calvin, XAFS for Everyone, Taylor \& Francis, 2013.

20. M. H. Han, E. Gonzalo, G. Singh and T. Rojo, Energ Environ Sci, 2015, 8, 81-102.

21. R. J. Clement, P. G. Bruce and C. P. Grey, J Electrochem Soc, 2015, 162, A2589-A2604.

22. R. Berthelot, D. Carlier and C. Delmas, Nat Mater, 2011, 10, 74-U73.

23. J. J. Zhu, J. Yang and X. N. Cheng, Solid State Sci, 2012, 14, 187-190. 